\title{
CAN LANGUAGES WITHOUT WRITING SYSTEMS PROVIDE NEW INSIGHTS IN LANGUAGE EVOLUTION?
}

\author{
CHRISTINA BEHME \\ christinabehme@gmail.com \\ Department of Philosophy, Mount Saint Vincent University, Halifax, Canada
}

\begin{abstract}
Given that (i) the first human languages presumably were simple and (ii) existing cognitive biases push language toward simplification and reduction it is perplexing that highly complex languages could evolve. Here I'll explore a potential solution for seeming paradox, that could also have implications for broader language evolution questions: the advent of writing. I hypothesize that writing allows humans to overcome the constraints of the "here and now bottleneck" and provides the foundation for linguistic innovations that feed back into spoken language. Systematically comparing languages that do and do not have writing systems could provide supporting evidence for this hypothesis. I propose that adopting this theoretical perspective could motivate important empirical work on language evolution.
\end{abstract}

\section{Introduction}

Language evolution theorizing faces many unique challenges, one of which is that we have no direct evidence for the earliest human languages: "Faded as soon as it is uttered, spoken language leaves no trace" (Burling 2005, 1). To circumvent this problem Burling suggests to depart from "two reasonably solid anchor points ... the behaviour of our closes primate cousins [and] modern human language" (Burling 2005, 2-3). Following this strategy immediately reveals a new puzzle. On the one hand, based on primate research (e.g. Arnold \& $\mathrm{Zu}$ berbuehler 2008, Call \& Tomasello 2007, Savage-Rumbaugh \& Fields 2000) we can be rather confident that first emerging languages of our distant ancestors were fairly simple. On the other hand, modern human languages are intricately complex. Given that currently existing cognitive biases push language toward simplification and reduction, one has to wonder how complex languages could have arisen. It has been suggested that "the pressure toward reduction is normally kept in balance by the need to maintain effective communication" (Christiansen and Chater 2016 a). But this suggestion only explains why modern languages are not any simpler, not how complex languages could evolve in the first place. 


\section{Language Acquisition provides clues for Language Evolution}

Intuitively, adopting Ernst Haeckel's slogan 'Ontogeny recapitulates Phylogeny' might provide important insights in the evolution of a complex (adult) language from a much simpler (early child) language. And indeed, in several recent publications it was suggested that language evolution and language acquisition should not be studied in isolation but as interlinked phenomena (e.g. Christiansen and Chater 2016 a, b). For example, (Christiansen and Chater 2016a) promise to provide "an integrated framework for explaining many aspects of language structure, acquisition, processing, and evolution that have previously been treated separately". Their main argument is that languages evolved to fit cognitive constraints on how linguistic structures can be learned and how utterances can be processed in real time. In turn language has an influence on cognitive mechanisms, favouring those that are heavily used in language production and comprehension. Christiansen and Chater proposed that "gradual increases in complexity can happen relatively quickly, as indicated by the fact that children can "outperform" the adults from whom they learn language (Singleton \& Newport 2004)". But, presumably, any newly emerging complexity would be subject to reduction and simplification pressures resulting in little or no net increase of complexity, unless there is a reason to maintain complexity. While the drive to communicate could provide such pressure, it has been argued convincingly that the complexity of grammar actually needed to support most daily activities of humans living in complex contemporary societies (let alone in environments our distant ancestors found themselves in) is substantially less than that exhibited by any contemporary human language (Gil 2009). Furthermore, it is unclear why certain features found in many languages (e.g. long distance dependencies) would arise in the first place: "If learners look first for local associations in blindly segmenting their language, subject to a crippling limit on short-term memory, it is unclear how long-distance dependencies could be stable in any lineage, much less universal" (Medeiros et al. 2016).

\section{Writing it down}

Spoken language's fleeting nature can be overcome by writing. Already Plato quotes an Egyptian myth according to which "[the invention of writing] will make the Egyptians wiser and give them better memories; for it is an elixir of memory and wisdom" (Phaedrus 274c).

Spoken language is not only fleeting but also one-dimensional (we can only speak and hear one word at a time). Yet, the world we experience is multidimensional and we routinely perceive several stimuli simultaneously. Story telling allows adding dimensions in language use but our memory limits how complex a spoken story can be. Writing is a tool that can overcome such limits. 
Once a word is written down it remains 'in place', allowing the reader to return to it at any time s/he wishes. Proponents of the "extended mind hypothesis" suggest that during many complex cognitive tasks "the individual brain performs some [cognitive] operations, while others are delegated to manipulations of external media" (Clark \& Chalmers, 1998; see also Logan, 2007). Some commentators of Christiansen \&Chater (2016a) stressed that written language could overcome some of the constraints imposed by the 'here and now bottleneck': "By the nature of texts as static visual objects, the effects of temporal constraints on information intake may be reduced or abolished. ... We acquire a portion of our vocabulary and grammar through written language, and we massively use text to communicate" (Baggioa and Vicario, 2016). Offloading part of the cognitive task to external media (the page of a book or the screen of a computer) also gives words 'permanence' and written sentences can greatly exceed the complexity of spoken sentences as this example illustrates:

An dem Schnittpunkte von Kurfürstendamm und Kurfürstenstraße, schräg gegenüber dem »Zoologischen«, befand sich in der Mitte der siebziger Jahre noch eine große, feldeinwärts sich erstreckende Gärtnerei, deren kleines, dreifenstriges, in einem Vorgärtchen um etwa hundert Schritte zurückgelegenes Wohnhaus, trotz aller Kleinheit und Zurückgezogenheit, von der vorübergehenden Straße her sehr wohl erkannt werden konnte. Was aber sonst noch zu dem Gesamtgewese der Gärtnerei gehörte, ja die recht eigentliche Hauptsache derselben ausmachte, war durch eben dies kleine Wohnhaus wie durch eine Kulisse versteckt, und nur ein rot und grün gestrichenes Holztürmchen mit einem halb weggebrochenen Zifferblatt unter der Turmspitze (von Uhr selbst keine Rede) ließ vermuten, daß hinter dieser Kulisse noch etwas anderes verborgen sein müsse, welche Vermutung denn auch in einer von Zeit zu Zeit aufsteigenden, das Türmchen umschwärmenden Taubenschar und mehr noch in einem gelegentlichen Hundegeblaff ihre Bestätigung fand. (Fontane, 1888, 1)

The use of written language allows Fontane to paint a detailed, multilayered picture of a complex scene in just two sentences. This is possible, in part, because German has evolved into a language with complex inflection and cases system which enables the reader to keep track of which adjectives modify which subjects even over considerable distance (e.g. " ... welche Vermutung denn auch in einer von Zeit zu Zeit aufsteigenden, das Türmchen umschwärmenden Taubenschar und mehr noch in einem gelegentlichen Hundegeblaff ihre Bestätigung fand.)

This example might demonstrate how an intricately complex grammar, once evolved, allows readers easily to follow complex stories. But, it seems unlikely that this intricately complex grammar sprang into existence instantaneously and, once more, the question arises how initial complexification arose. 
Plato, again, may suggest an answer: "when [words] have once been written down they are tumbled about anywhere among those who may or may not understand them ... and they have no [speaker] to protect them; and they cannot protect or defend themselves" (Phaedrus, 275c). Plato's point is crucial. During a verbal conversation the listener can ask for clarification and the speaker can provide as much detail as is needed for the successful transfer of the intended message. But the pages of a book cannot perform this task. Here only those messages can be "successful" that anticipate and answer questions of actual and potential readers. The written text has to anticipate questions, reduce ambiguity, and increase informative content. In order to accomplish this task reliably written languages needed to evolve a kind of precision that is different from that of required in spoken language. At the same time, the permanence of written language allowed for innovations inaccessible to spoken language that could provide this new kind of precision. The previously mentioned complex inflection and cases system of German is one way of solving the problem. Christiansen and Chater (2016b) stress the importance of linguistic experience for language learning and processing, and highlight reading as one important source of experience. Written texts allow for easier integration and fixation of such complex language properties as long distance dependencies, object relative clauses, and multiply embedded recursive clauses. Given that those properties add expressive power to languages they provide tangible benefits. Having a medium that overcomes the fleeting nature of spoken language could have provided an anchor point for those structures. Once they became part of written language they would have also been used increasingly in spoken language and, perhaps impacted the brains' ability to process those structures.

\section{From philosophical speculation to scientific research}

Virtually all languages that have been investigated by language evolution researchers had writing systems for hundreds or even thousands of years. If the invention of writing was indeed the launch-pad to any Baldwinian-type evolution, then most currently researched languages would have been affected by this change. It has been suggested that “... the earliest written documents already display the full expressive variety and grammatical complexity of modern languages" (Jackendoff 1993, 32). Additionally, many experimental designs rely heavily on written language (e.g. self-paced reading tasks, word recognition tasks, etc.). As a consequence, we may be learning more and more about the evolution of written language and making some erroneous assumptions about the earlier evolution of spoken languages.

To test the hypothesis I introduced in section 3 empirical one would need to conduct detailed comparisons of complexity parameters of languages that do and that do not have a writing system. "Ethnologue (20th edition) has data to indicate that of the currently listed 7,099 living languages, 3,866 have a developed writing system ... The remaining 3,233 are likely unwritten" (Simons \& 
Fennig 2017). Those 'remaining languages' could provide a (albeit rapidly narrowing) window into earlier evolutionary stages of the interplay between cultural and biological language evolution. Especially language acquisition research of languages without writing systems might be a promising research avenue. Currently studies on such languages are rare (Gordon et al. In progress for Pirahã) and detailed comparative work between languages that do and do not have writing systems is nonexistent. Given that researchers are often influenced by expectations what they might find in a language (e.g. Everett, 2009) such research is especially challenging.

In part comparative research between languages that do and that do not have a writing system might have been hampered by a "longstanding linguistic axiom - that all languages ... are similar in complexity, and have been so at all times in the past" (Sampson, 2009a). Researchers paralyzed by ideological fears should remember that language evolution is not a race towards some perfect language and, therefore, more complex languages, or languages with a writing system are not 'superior' to others. Rather languages ought to be evaluated by how well they fit the communicative needs of their respective communities. From that perspective, a language that allows the complex sentences of German is not any better (or worse) than a language (like Pirahã) that does not.

Of course, it has been known for a long time that "unwritten third world grammars often contain highly sophisticated structural features" (Sampson 2009b). But it would be desirable to find out whether there are systematic differences between the complexities of languages that do and that do not have a writing system. For example, it turns out that Jackendoff was wrong about the unchanging complexity of written languages. Guy Deutscher documented that "the earliest recorded stages of Akkadian [lack] finite complement clauses ... [and that] complement clauses [are] gradually developing out simpler, non-recursive which did exist in the early records" (Sampson, 2009b). It is of course possible that cultural changes, that occurred independently of the writing system, generated novel communicative needs for which recursive structures provided a solution. For this reason one needs to compare languages systematically. If it turns out that only languages with a writing system have certain complex properties (e.g. long distance dependencies or multiply embedded recursive clauses), then one might argue with confidence that a writing system is a necessary condition for the evolution of those language properties. If languages with a writing system are statistically more likely to have those properties, then a writing system is not necessary (but perhaps beneficial) for their evolution. And if languages with and without a writing system are equally likely to have those properties, then a writing system is irrelevant for their evolution. 
Further it would be good to compare systematically the kids of messages that are most prone to error in languages with and without a writing system. Over centuries, even for language with a writing system, writing was a privilege of the educated upper classes. Their needs for communication and entertainment determined what was written town and passed on to the next generations. Only recently has literacy been extended to most speakers of many language with writing systems. And, the recent advent of Twitter has greatly reduced the linguistic complexity of some speakers and also shown that existing written language is ill adapted to unambiguous transfer of information in very limited space. Language evolution researchers might win important insights from monitoring how this novel cultural phenomenon impacts complex language properties.

Finally, it would also be important to find out whether there are complex language properties that are only found in languages without a writing system. This proposal may seem paradoxical since all languages evolved from languages without a writing system. However, because language evolution is not 'aiming' at some ideal end-sate, complexity does not always increase. In fact, Plato had already suggested that the invention of writing might have an adverse effect: " [the letters] will create forgetfulness in the learners' souls, because they will not use their memories [but trust the written words]" (Phaedrus 275a). Because a language without writing system places a greater burden on working memory it may have evolved specific cognitive tools that are no longer needed when writing allows one to 'extend' one's mind and 'offload' part of the cognitive task. Again, only detailed empirical research can (dis)confirm these speculations.

Overall, I believe that a systematic comparison between languages with and without writing systems can provide new perspectives on language evolution research and, perhaps, help answering the question "Why did complex languages evolve in spite of cognitive biases pushing towards simplification and reduction.

\section{References}

Arnold, K. \& Zuberbuehler, K. (2008) Meaningful call combinations in a nonhuman primate. Current Biology. 18, 5, R202-R203.

Burling, R. (2005) The talking ape. Oxford: Oxford University Press.

Call, J. \& Tomasello, M. (2007). The gestural communication of apes and monkeys. Mahwah, NJ: Lawrence Erlenbaum.

Christiansen, M. H., \& Chater, N. (2016a). The Now-or-Never bottleneck: A fundamental constraint on language. Behavioral and Brain Sciences, 39

Christiansen, M. H., \& Chater, N. (2016b). Creating Language. Cambridge, MA: MIT Press.

Clark, A. \& Chalmers, D. (1998). The Extended Mind. Analysis, 58, 1, 7-19. 
Everett, D. (2009). An interview with Dan Everett. In: G. Sampson, D. Gill, and P. Trudgill (Eds.) Language Complexity as an Evolving Variable. (pp. 213-229). Oxford: Oxford University Press.

Fontane, T. (1888). Irrungen Wirrungen On-line: http://gutenberg.spiegel.de/ buch/irrungen-wirrungen-4457/1 accessed 14/01/2018.

Gil, D. (2009) How much grammar does it take to sail a boat? In: G. Sampson, D. Gill, and P. Trudgill (Eds.) Language complexity as an evolving variable. pp. 19-33. Oxford: Oxford University Press.

Giosuè B. \& Vicario, C. M. (2016). Language processing is not a race against time Behavioral and Brain Sciences, 39.

Gordon, P., Kirby, E., Tang, J., Zaleznik, E., Maldonado, D., Orr, A., Gazman, Z., Truong, S., Cheng, R., Shi, W., Wang, Y., Madden, S., \& Everett, D. (In Progress). Pirahã Motherese.

Jackendoff, R. (1993). Patterns in the mind: language and human nature. New York: Basic Books.

Logan, R. K. (2007). The extended mind: The emergence of language, the human mind and culture. Toronto: University of Toronto Press.

Medeiros, D., Piattelli-Palmarini, M. \& T. G. Bever (2016). Many important language universals are not reducible to processing or cognition. Behavioral and Brain Sciences, 39.

Plato (1937). Phaedrus. In: Jowett, B. (Translator) The dialogues of Plato. pp. 233- 284. New York: Random House.

Sampson, G. (2009a). Preface. In: G. Sampson, D. Gill, and P. Trudgill (Eds.) Language complexity as an evolving variable. pp. vii-viii. Oxford: Oxford University Press.

Sampson, G. (2009b). A linguistic axiom challenged. In: G. Sampson, D. Gill, and P. Trudgill (Eds.) Language complexity as an evolving variable. pp. 1-18. Oxford: Oxford University Press.

Savage-Rumbaugh, E.S. \& Fields, W.M. (2000) Linguistic, Cultural and Cognitive Capabilities of Bonobos (Pan paniscus). Culture \& Psychology 6(2), 131-153.

Simons, G. F. \&. Fennig, C.D. (Eds.). 2017. Ethnologue: Languages of the World, Twentieth edition. Dallas, Texas: SIL International. Online version: http://www.ethnologue.com. accessed 14/01/2018. 